\title{
Ethnologies
}

\section{The New York Yankees and the conservative use of space}

\section{Benjamin R. Bates}

Volume 24, numéro 1, 2002

Espace

Space

URI : https://id.erudit.org/iderudit/006537ar

DOI : https://doi.org/10.7202/006537ar

Aller au sommaire du numéro

\section{Éditeur(s)}

Association Canadienne d'Ethnologie et de Folklore

ISSN

1481-5974 (imprimé)

1708-0401 (numérique)

Découvrir la revue

Citer cet article

Bates, B. R. (2002). The New York Yankees and the conservative use of space. Ethnologies, 24(1), 201-224. https://doi.org/10.7202/006537ar

\section{Résumé de l'article}

À New York, le " Canyon des Héros ", la partie de Broadway qui s'étire entre Wall Street et l'Hôtel de Ville, sert souvent d'espace de célébration pour des évènements sportifs, militaires ou politiques. Cet article présente une analyse du déroulement de l'un de ces défilés - celle de la victoire des Yankees de New York en 1998 - et de sa (re)présentation par NBC. À partir du concept de « la perruque » de Michel de Certeau, cet article soutient que la combinaison des niveaux de lecture multiples de cet espace (macro, micro et entre-deux) nous permet de comprendre comment s'entremêlent et se tissent plusieurs écheveaux de symboles pour aboutir à une représentation spatiale conservatrice sur les plans politique et économique. Cet article présente les implications de cet usage conservateur de l'espace dans l'élaboration de la théorie de l'espace et de l'intervention critique.
Ce document est protégé par la loi sur le droit d'auteur. L'utilisation des services d'Érudit (y compris la reproduction) est assujettie à sa politique d'utilisation que vous pouvez consulter en ligne.

https://apropos.erudit.org/fr/usagers/politique-dutilisation/ 


\title{
The New York YankeEs ANd the Conservative Use OF SPACE
}

\author{
Benjamin R. Bates \\ Speech Communication, University of Georgia
}

Winning isn't everything. It's the only thing.

(Vince Lombardi)

Sports events, as the ancient Greeks knew well, could be used as a substitute for war in city-state competition, hence the creation of the ancient Olympics. Although the founder of the modern Olympics, Pierre de Coubertin, envisioned an event free of consumerism and nationalism, they are now a forum for national conflict and rivalry (Riggs 1993). As Katz and Dayan (1985) argue, the Olympics are a coronation for the king of nations and a celebration of conflict, contestation, and conquest. The Olympics now reinforce nationalism and hyperpatriotism as fundamental values rather than the equality, liberty, and fraternity that are the official reasons for the Games (Rothenbuhler 1989). In addition, commercialism and consumerism are now values supported by the Games, in contradiction to de Coubertin's vision (Farrell 1989). Truly, the Olympics are a substitute for war; national aggression, the fight for supremacy, and economic competition are all enfolded within the Games.

Although not a substitute for civil war, on an intranational level sports may serve the same purpose as the Olympics. Sports teams can elevate the recognition of a city on the international and national business, convention, and tourism scenes. Winning the national championship title in any sport makes a city's name synonymous with a nation's best, though only briefly. As marketers well know, winning in a sport allows a city to claim greatness, as evident in the crass 
commercialism that transformed the Atlanta Braves and the Dallas Cowboys of the early 1990's into "America's Team(s)". Perhaps the existence of sports teams is one factor contributing to Yi-Fu Tuan's statement that "Places can be made visible by a number of means: rivalry with or conflict with other places, visual prominence, and the evocative power of art, architecture, ceremonials and rites. Human places become vividly real through dramatization" (1977: 178).

Sports are, fundamentally, agon between two sides and between two cities. In choosing schedules, this aspect of sports is central to the search for higher ratings (Russell 1994; Van Weert and Schreuder 1998). Further, broadcasting increases the exposure of a city's teams, on both regular television and special channels like ESPN and CNNSI (Higgins 1999; Mitrano 1999). The dramatization of cities on television, through the contest itself and through the commentators' reflections on rivalries, increases the importance of successful sports franchises to a city.

Walter Benjamin argued that, "What is true of the image of the city and its inhabitants is also applicable to its mentality" (1986: 114). After a stay in New York, Benjamin might conclude that the image of a city provided through sports is similarly indicative. Indeed, as Mayor Rudolph Giuliani stated, "The resilience and determination of the 1996 Yankees is a metaphor for the entire city of New York, where we have battled back in the face of the doubters and the doomsayers to once again make New York a city of growth, opportunity and hope" (1996: 3). What Giuliani leaves unsaid, however, is for whom this battle was fought. The desired appearance of the parade is to present an image of citywide freedom and joy that the masses can participate in.

Focusing on imagery has its dangers. The consumption of sports teams as metaphors for a city might just as easily lead to incomprehensibility. Simply put, the image of a city provided by a sports team is not reflective of the city's whole. To simply accept Giuliani's statement then, would bring about a retort similar to Baudelaire's response to the promotion of cities through arts - it leads to "a state of mind bordering on vertigo or idiocy" (1997: 121). Although arts and sports may construct a representation of what is good and noble in a city, they are impermanent and replaceable. If taken as a permanent representation of the city, the stadium or museum can evoke a false understanding because it allows the appearance of freedom and contestation within a highly constrained and limiting space. 
Although the New York Yankees World Series victory invoked city pride and collective joy, it disappeared as soon as the next pennant race began. However, for the moment in which the sports team is the dominant image of a city, discussions of how the sports team represents the city can be fruitful. Shortly after their 1998 victory over the San Diego Padres, the New York Yankees returned to New York for a parade in their honor. The parade stretched from Wall Street to City Hall, replicating the route of other city, state, and national heroes as they moved through the "Canyon of Heroes". NBC, the network that had covered the World Series, packaged the celebration and transmitted the images to the nation and beyond.

Because of this transmission, the traditional New York Yankees victory parade serves as a media representation of New York City. By following the team from the beginning of the parade to the speech given by Giuliani at the end, an image of New York City, that reflected by the use of the "Canyon of Heroes", was created. The purpose of this essay is to explore this image of the city reflected by the use and (re)presentation of space in New York City through a variety of symbols shown in the media. This essay begins with a discussion of New York City's most prominent feature, the grid, and demonstrates how the grid does not provide a full explanation of structural forces in New York City. Then, after discussing the limits of the macro and micro views of exploring and (re)presenting space, I offer a mediation between these two views through Michel de Certeau's la perruque. After clarifying this concept, I turn to the parade itself. As NBC's broadcast of the parade shows, several threads of symbols - the parade route, the Yankees, the framing, the fan's garb, and more - are woven together to create a (re)presentation of New York City as a space that celebrates the current political and economic orders. The fabric of this representation has been unraveled into symbolic threads to treat each symbolic set or action separately in this analysis. Finally, I offer some implications that media (re)presentations of space and place have for spatial theories. However, before this discussion can begin, it is necessary to explore the nature of New York City's most dominant feature, the grid.

\section{Grids}

Perhaps the most prominent feature of New York City is the pattern in which it is laid out. As a larger text, the nearly right angle grids that cause streets to run east-west and avenues to run north-south allow a 
coherent structure of roads so that even the novice tourist can quickly figure out directions. As a grid, the road plans of New York City create an overlay that forces disparate spaces into a structured organization. Although this helps to ensure rapid transport of people and goods through the city, the grid formation also creates a vacuous uniformity at times. As James Kunstler puts it,

The scheme accelerated the city's already rapid growth, but in doing so it wiped out the geographical features... that characterized rugged Manhattan island, and replaced them with an unrelievedly mechanistic layout of linear streets and avenues that did not lend itself to memorable cityscape - one block was the same as any other block, and, indeed, when built up they would appear interchangeable (1993: 32).

Although Kunstler sees some benefits to the grid pattern, it is clear that he disapproves of it. The sacrifices made for roadways allowed the identity of indigenous places to be erased.

Some see the lack of character indicted by Kunstler as an advantage for New York City. Rather than being trapped in a system that requires preservation out of some (pre)modern fascination with location, the grid formation sponsored by New York City actually allows a form of liberation from the fixity of space. As Richard Sennett argues, a city planned along a grid formation limits the conceptualization of space. Instead, the very schematic planning of the city is what allows for a break away from the prescribed mold. "The lack of directives in New York's plan means spaces can easily be swept clear of obstacles, those obstacles constituted by the accretion of stone, glass, and steel from the past" (Sennett 1994: 360). Because there are no permanences in New York requiring users to regard a particular space as sacred, it is possible to simply erase past associations with a location on the grid and replace it with a new understanding. This almost utopian erasure creates the grid as a site of unlimited freedom.

Neither Kunstler's mechanization of New York nor Sennett's utter freedom is absolute. As Kunstler notes, the creation of Central Park, the accommodation of Broadway, and the spaghetti junctions brought about by the incursion of interstate highways broke the linear disciplining of the city. In addition, variation in height allows some diversity within this structure. However, even with the lines broken by these anomalies, the overall structure created by endless blocks of right angled roads and rectangular islands of homes, businesses, and plazas 
remains largely in place. To meet the demands of body-society as a machine, New York City's grid formation creates a structure that is difficult to question and nearly impossible to change in the face of the established tradition (Sennett 1994). As Benjamin might say, New York City exists "at the present moment in which 'all factuality is already theory' and which may refrain from any deductive abstraction, from any prognostication, and even within certain limits, from any judgement" (1986: 132). In short, it is unnecessary to ask whether New York's grid formation is the best option; the fundamental concern is what already is. Legal enforcement and the assumption that grids provide for efficiency create "good reasons" to enforce the grid pattern. By laying out this grid in a manner that gains compliance through coercion (by way of governmental regulation) and self interest (by appealing to personal profit motives), the city can be considered a structured structure that is constantly self structuring. ${ }^{1}$

To explain the utility of the grid, De Landa argues that it is

the best and quickest way to organize a homogenous population with a single social purpose. On the other had, whenever a heterogeneous group of people comes together spontaneously, they tend to organize themselves in an interlocking urban pattern that interconnects them without homogenizing them (1997: 30-31).

In the case of New York, some mediation between these two types of grid formations is necessary. It would be difficult to argue that New York City is a homogenous zone. Just on Manhattan, one can see an economically, racially, culturally, and ethnically diverse population. Business types range from high finance to waste reclamation, with military, government, and utilities adding additional layers of economic and political complexity. To argue that these groups form a homogenous polity organized around a single purpose becomes out of place. However, to argue that this diversity came together "spontaneously" would be to ignore the social and physical engineering efforts that brought people into the city (Kunstler 1993). Neither of De Landa's organizational patterns explains the grid formation that occurred (and occurs) in New York City.

1. This formation is necessarily complex. Although Kunstler (1993) emphasizes the corporate profit motive that allows individual people and businesses to support the grid pattern, he does not recognize the governmental interest in creating these patterns. Sennett (1994), on the other hand, recognizes the governmental interest in plotting the "roman grid", but does not pay enough attention to the embodiment 
What, then, is a critic to do with this grid? The answer is to explore a mediation where the term emphasized is not heterogeneity of populations (as divided by grid lines) or homogeneity (as made parallel by grid lines). Rather, we can note that, "Space occurs as the effect produced by the operations that orient it, situate it, temporalize it, and make it a function of polyvalent unity of conflictual programs or contractual proximities" (de Certeau 1984: 117). Although the structural program is worthy of analysis, to focus on the street grids alone, at the expense of social interactions, would exclude human experiences of these spaces. Rosalyn Deutche's (1993) analyses of Battery Park and Union Square in New York show that, if one focuses on the streets only, programs that create personal and societal damage are allowed because of the mechanistic scheme engendered by the transport/ transit oriented view adopted by grid planners.

Neither the absolute micro or macrosocietal view of space allows a full realization of its importance. The former allows individualization to such a degree that it becomes an idiosyncratic and aberrant interpretation of a space. The latter creates a view that excludes the individual. Although the latter may track the flow of thousands, in a statistical sense, it does not have a great degree of heuristic value when attempting to explain small(er) groups of people. This problem is the subject of Michel de Certeau's discussion of space and its (re)presentation. His principle of "la perruque" negotiates between the micro and macro views of space, and of the things that are formed by and formative of space.

\section{La Perruque}

Without going into the details of a thesis that disqualifies the ideological divisions between kinds of knowledge, and thus also their social hierarchization, we can at least point out that this tactic ties together (moral) freedom, (esthetic) creation, and a (practical) act three elements already present in the practice of la perruque, that modern day example of an everyday tactic (de Certeau 1984: 74).

of enforced patterns by people and corporations in their own interest. By reading both motives into governmental, corporate, and personal action, we can realize, as Foucault (1999) and Bourdieu (1998) do, that both levels of interest and both levels of (re)production must be recognized for a full model of how structures are created, enforced, and justified. 
This perruque indicts both the macro and the micro levels of analysis. De Certeau argues that individual experience must be related to the general structure of everyday experience. If one focuses on the micro level of la perruque, one will become overly embroiled in the ability of individuals to resist structures of domination, ignoring the forces that prevent expression of dissatisfaction with the system. If the critic focuses only on the macro level, though, s/he is likely to see only the high level structures of capital formation and dispersal, and not account for opportunities for resistance. Thus, it is not enough to take the "god's eye" view that Harvey (1989) derives from de Certeau, wherein a macrotheoretical model is used to show how structures ensure economic disparities. Nor is it enough to derive from de Certeau the idea that only individual experience matters, as Blair, Brown and Baxter would argue (1994). In interpreting cities and their effects on populations, theorists have not made use of la perruque and its negotiation between macrostructural considerations of and microstructural interactions with space. Instead, some have tried to make one system of understanding space take precedence over the other.

This argument over what is truly important in the analysis of space is not simply theoretical; it shapes critics' and users' critical and praxical interpretations of space. When discussing the divide between the metainterpretation and the personal interpretation, we seem to find ourselves at the difficulty described by Trow.

The middle distance fell away, so the grids (from small to large) that had supported the middle distance fell into disuse and ceased to be understandable. Two grids remained. The grid of two hundred million and the grid of intimacy. Everything else fell into disuse (1997: 47).

Because critical and praxical use of space has focused either on the macrostructural and macronarrative interpretation or the microstructural and micronarrative interpretation, intermediate zones appear to be lost. Trow concludes that analyses of culture that do not seek out some form of negotiation between the grid of two hundred million and the grid of intimacy are necessarily flawed. The grid of two hundred million leads to a generalization of motives, uses, and understandings, but is unable to explain individual motivations. The grid of intimacy becomes solipsistic in its explanations and it is easily countered by the analysis of the next grid of intimacy. Trow, then, aims for some middle ground, but argues that the de-emphasis of the middle 
ground makes current theoretical paradigms inadequate for exploring it. Despite Trow's pessimism, there is a means of interpreting that middle ground that operates between the two grids of analysis indicted here. Although neither the micro nor the macro view provides a full explanation, a negotiation that draws elements of analysis from each may provide a better interpretive framework. As we move to explore a city, a structure that is far from intimate but not as depersonalized as the national scene, a means of exploring this middle ground must be found.

\section{Tightrope}

While la perruque has been denied a full interpretation in the literature, it provides a good framework for negotiating between the macro level of analysis and the micro. Although one could argue that the performance of la perruque is to perform one level of analysis followed by the other, such an action would not be true negotiation. Instead, the understanding that a critic should derive from de Certeau is that of a tightrope walker who must take into account the larger view that s/he is presented with as well as taking into account particularities that might cause her or his analysis to fail (Achter and Brow 2000). Similarly, Soja argues that "both the views from above and from below can be restrictive and revealing, deceptive and determinative, indulgent and insightful, necessary but wholly insufficient" and that one should not set them up in opposition but in relation (1995: 314).

To create New York City as a simple grid and to observe it from above, would be to look at structure only, excluding experience. The view from above, as de Certeau (1984) rightly points out, is also one that uniquely privileges the male gaze and emphasizes structure, control, and domination in theory and practice. To adopt a view from the street, one in which metanarratives and metastructures are unseen, would limit discussion to the fleeting gaze of the citizen. The meaning of personal experiences is obscured unless it is framed against larger structures of interpretation: "blindness to experience is in fact a common human condition" (Tuan 1977: 201).

Neither personal experience nor the larger view can provide a complete representation. Deutsche makes this point clear when she notes, "Impartial vision is possible only in the presence of an object that itself transcends partiality and is thus independent of all subjectivity" 
(1996: 310). Deutsche provides a hypothetical interpretation of the social world that might be able to meet the demands of impartiality, but concludes that it is impossible to unbiasedly represent any social space. However, to reject all attempts at an "objective" relation to the social is similarly a mistake. As Deutsche argues, objective material conditions of "simultaneous deindustrialization and reindustrialization, decentralization and recentralization, and internationalization and peripheralization" are objective material conditions that must be accounted for (1996: 73). In this sense, the analyst must be a tightrope walker who will be able "to remain balanced between a corporeal presence... supportive of the analysand's assertions and the necessary separation... which evokes or signals the ambiguity of these assertions (de Certeau 1986: 55). If the asserted reality of the voyeuristic view is embraced unquestioningly, the analyst will become trapped in prestructured conclusions that come from the assumptions of voyeurism. However, if one completely rejects this view, then individual perspective merely becomes a set of irreconcilable fragments, as all attempts at translating micronarratives coherently require some embrace of an overarching interpretive scheme.

De Certeau's tightrope metaphor allows the necessary skepticism of voyeuristic views to be noted when viewing from above, but does not fall into a militant particularism that makes a coherent story impossible. This tightrope can be seen as fundamental to understanding and operating within society, and it is the view that most people unconsciously accept. As he notes,

This system, all the way from science to the mass media, unleashes a monstrous proliferation of intermediary places, a neutral standardized zone in which is endlessly repeated the form of an abstract universal filled, now and again, by particulars on which its modulation is based (1997a: 34).

Thus, unlike Trow's assertion that we are trapped between the intimate grid and the national grid, there are many in-between perspectives. However, we cannot argue that all of the various modulations of experience will utterly diverge. Rather, materiality allows the various modulations to share common elements, creating a standardization of experience. This standardization is not absolute, as each person will experience particular elements of that reality and translate them somewhat differently. What happens, instead, is that 
there is some level of (re)cognition and (mis)understanding shared by persons that have a relatively homogenous cultural experience (Bourdieu 1998). Although the grid of intimacy is likely to result in nearly identical (re)presentations of reality ${ }^{2}$, the grid of the nation is unlikely to perform such a function. By using the media to create a shared understanding of a space, New York City, the interpretation of the space by media (re)presentation can shape understandings on the level of the intimate grid and the grid of two hundred million. The New York Yankees victory parade operates in-between the micro and macro views of the city - the space between two extremes. Although it is important to look at the parade from above (to see the structural power that it masks) and below (to see the relationships allowed from an individual's perspective), the media (re)presentation provided by NBC's coverage of the parade allows us to view the more important "both/and also..." of micro and macro interpretations (Soja 1996).

\section{Text}

Although NBC's coverage was a fleeting image, as the moment (re)presented in the parade is one that cannot be completely reproduced, a permanent understanding of New York City is not the goal of this project. The parade's effects are replicated in iterations of the parade in other World Series victories, as well as in other sports, military, and political celebrations. What is important here is how the projection of the Yankees through both physical space (the streets of New York) and mental space (in terms of what that space means) incorporates the view of New York from both above and below. In this sense, the media (re)presentation of the victory parade is one that walks the tightrope of la perruque. Instead of embracing a simple view of the route of the parade (above) or the actual experience of a parade-viewer on the street (below), watching the parade on television allows both views simultaneously. Although the televisual view is likewise incomplete, the both/and also view provides a larger understanding of the parade than a single view would allow. Moreover, television allows editors to access several different strands of symbols and to weave them together into a coherent narrative. Although this project portrays itself as specific to the city, the arguments leveled here have greater

2. Indeed, the law assumes that a husband and wife are a single entity, adding a juridical justification for this theoretical point. 
applicability in how media (re)presentations are creative of, while also representative of, space in general. The media (re)presentation of New York City portrayed provides a necessarily contingent view of the celebration of citywide victory contained within a designated space. This media (re)presentation of the city was chosen because of its accessibility as a reference point for New Yorkers and those who live beyond, and for its status as a concomitant mystification and demystification of the power nexuses of New York. In short, the analysis will explore how media images allow us to "submit to the tacit law of a particular place... the sum of determining factors that establish the limits of a meeting of specialists, a sum that circumscribes with whom and about what a change about matters of culture is possible" (de Certeau 1997a: 123).

\section{Analysis}

This analysis begins by noting that there are at least three different ways to view the New York Yankees victory parade: from above, from below, and from in-between the above and below. When taken from above, the view of the map, the meaning of the New York Yankees victory parade is simple, as is its use of space. From above, the route that the Yankees take moves from the intersection of Broadway and Wall Street via the "Canyon of Heroes" to City Hall. When taken from above, this can be interpreted as moving from a financial district that holds structural power in the global capitalist order to another part of the structuring order, the seat of government. By tying the two together into a narrative, Broadway becomes a connection between the forms of structural power. The New York Yankees, as an entertainment device, are of little importance to the view from above other than the fact that they are forced to move between these two locations of power. As such, they are paying homage to the capitalist system that allows the sale of merchandise, tickets, and the ethos of the Yankees through media outlets and to the governmental system that allows tax breaks, mass transit stops, and police protection necessary to operating a sports franchise in an urban environment.

The view from above allows us to see the parade route as a connection between enabling social forces that dictate the ability of an entertainment medium to succeed in the American system. As such, the parade route serves as an analogy for the process that a television 
producer, sports team, or other entertainer must perform - one that pays homage to both capitalism and government. Events like parades "involve first a logic of a 'place' that produces and reproduces, as its effects, militant mobilizations, tactics of 'making people believe', and ecclesiastical institutions in a relationship... with respect to the established powers" (de Certeau 1984: 184). The direct relationship between capitalism, government, and the ability of a group to display itself to the American people is not within the direct view of the person on the street. Instead, one must look from above to be able to determine the relationships mapped by the parade. It is traditional for a victor to proceed through the "Canyon of Heroes" to be congratulated by an adoring present and mediated audience. Without some cognizance of the view from above, the fact that the "Canyon of Heroes" provides a narrative tie between structural economic power and structural governmental power is sure to be elided. The view from above makes the ecclesiastical function of the parade clear: one must pay tribute to both the capitalist order and the seat of government to pass through the rites of becoming a true hero.

The Yankees are not alone in serving this ecclesiastical function. Their consent to the parade route reiterates and reinscribes the "Canyon of Heroes" as a place and the values that it represents. The ticker-tape parade tradition dates to at least 1886 when the Statue of Liberty was dedicated. Since then, parades have been held to honor individuals who have contributed to the maintenance of the dominant economic and political orders. Other honorees include Charles Lindbergh, Winston Churchill, Charles de Gaulle, World War II soldiers, and the Apollo 8 astronauts (Roche and Deacy 1998). With these honorees, a clear pattern emerges: those who are honored by a ticker-tape parade are involved with the military and industrial complex. Even potentially subversive figures participate in this parading of the power of the establishment. General Douglas MacArthur and Nelson Mandela are such figures. MacArthur was disciplined for disagreeing with President Truman's orders in the Korean conflict. Mandela was freed from prison after decades of resisting Aparthied. Nonetheless, these figures still pay homage to and serve as representatives of the power structure. MacArthur was removed for being overly aggressive in Korea, not for resisting military action on behalf of an ideological conflict. Mandela was honored only after he consented to using nonviolent and nonrevolutionary modes of social change within the South African 
system despite the fact that it was still plagued by vast wealth and power disparities. The figures honored by these parades are participants in the economic and governmental order celebrated in the "Canyon of Heroes". These marchers are not co-opted by the establishment. Instead, their choice to be put on display in the "Canyon of Heroes" indicates consent to, if not active agreement with, the structure of power that is celebrated by the parade. Participating in the narrative formed by the parade route supports the argument made by the parade, that one cannot occupy the space of a hero without paying homage to the forces of capitalism and liberal politics. By marching, each participant reveals his or her commitment to the system and has the effect of making people believe in that system.

To assume that only the "god's eye" view can see these structural relationships would assume the absolute naiveté of those viewing the parade. Additionally, it implies that the parade viewers are only aware of the view from below. As recent commentaries on sports discourse (Ficher and Ozanian 1999; Goldberg 1998; Yoder 1997) have noted, the average fan, sports commentator, and academic critic each realize that sport is commodified, as team owners increase ticket prices, cities offer stadiums to sports leagues, and individual players seek higher salaries. Although the parade masks the relations of capitalism, government, and sport by emphasizing the view from below, when the parade viewer is led to look up from the street, the view that $\mathrm{s} /$ he receives is designed to impress the parade viewer with the strength and inevitability of the structural order in which the parade takes place. Just as realistic ${ }^{3}$ settings are designed to dampen the awareness of enclosure and captivity at zoos and aquariums (Davis 1997), the artificiality of the steel buildings and rubberized pavement of New York City remind the person that $\mathrm{s} / \mathrm{he}$ is bound by the laws and structures of the city.

The enclosure provided by the city experience recalls the other prominent feature of New York City: its height. New York is a vertical city. Depending on one's placement in terms of height, a view from above or below can become the main emphasis. The role of height comes into play when we examine the micro, macro, and combinatory views of the city. New York is not a surveyor's plat, the macroconceptual view at the extreme. It is not a flat land when experienced on the

3. Meaning reflective of the wild or natural habitat of an animal. 
ground either, a view that micro analysts might assume based on textures that are seen, but rarely felt by the participant. Instead the (em)placement of perspective in different levels of height requires us to understand New York City as observed from different angles. Since neither view provides a complete understanding of how space is (re)presented by the parade, we should try to account for height, its impact on perspective through the angle of viewing, and the incompleteness of perspective. We must realize, as Soja does, that

Understanding the city must involve both views, the micro and the macro, with neither inherently privileged... The appropriate response to the micro vs. macro choice is thus an assertion and creative rejection of the either/or choice for the more open-ended both/and also... (1996: 310).

Only the both/and also view afforded by the mediation of the television camera can provide a (more) complete view of the "Canyon of Heroes". The media (re)presentation of the parade is a creative rejection of the either/or choice imposed by the interpersonal or macrostructural critics. The different angles of viewing space are enacted consciously throughout the parade coverage.

The most telling use of different angles to observe space is the parade's coverage of the first baseball player to be seen in either the physical parade taking place in the "Canyon of Heroes" and in NBC's coverage: Darryl Strawberry. As the convertible carrying Strawberry nears the first camera, the viewer at home is treated to the view of the person standing on the sidewalk. As this ground-level view is adopted, the NBC crew (1998) states, "What a marvelous low angle this perspective provides". On the street, a person is grounded in New York City — s/he can touch, feel, and smell the city close up while viewing the parade. The ability to experience the parade as it passes reflects the experience of the fast moving city of New York. The partiality of perspective reminds the viewer that $\mathrm{s} /$ he must keep moving in relation to other moving objects in a space that both limits and allows freedom of perspective. Although the view from below is available for only a few seconds, the intimacy and immediacy it provides implies that that the best perspective is from the sidewalk. Despite this strong impact, the viewer is soon told that this view may not be the best. As the angle switches to that given by a camera based on a helicopter above the parade route, the announcers state, "What a spectacular shot looking down from Chopper 4" (NBC 1998)! Strawberry looks much smaller, but we are 
able to study him more carefully as his convertible passes, and the viewer is assured that $\mathrm{s} / \mathrm{he}$ can return to a similar view freely. The chopper makes the parade seem like a hypertext as it allows this movement and return. The beginning and end of the parade are always the same, but each point in the parade can be (re)discovered and (re)covered as the parade traces its route. Yet, this displacement from the linear viewing of the parade as it passes from the street-level viewer's fixed standpoint makes the view incomplete as the nodal point is removed from the television viewer's perspective.

Throughout the coverage, the viewer at home is led to see her/his view as partial. The views from above or below, however, are seen as even more incomplete. The people on the sidewalk realize that their view is limited. Indeed, viewers see ground-level spectators climbing lampposts as high as possible to make up for the inadequacy. ${ }^{4}$ The crew of NBC, realizing that the above view is incomplete, is compelled to move to street level interviews to gain the perspective from below. However, it is only the viewer at home, taking advantage of the televisual gaze, who is able to gain both perspectives. S/he, though, must realize that her/his own view is incomplete, as s/he is only able to see what the camera operators and their editors allow to be shown. All views must be adopted to the fullest extent possible if the use of space in celebration is to be understood. Further, the (inter)mediation provided by the television sponsors creates a perspective that is different from either the (least) mediated perspectives from either above or below. The complementarity provided by the televisual perspective on the "Canyon of Heroes" allows the understanding of la perruque illustrated here to be (more) complete. The televisual combinatory perspective provided by the parade coverage indicates more than the simple geography of street formations and population distributions given by the view from above. Buildings, by their height, block a view of the grid from below even as

4. These spectators appear to be above street level. Certainly, their perspective of the event is different from the view from the street, or from above, or that on the TV. However, this does not mean that they mediate between the above and below views. Instead, they are simply the street view, only more limited. Having placed themselves on the wall or lamppost, they have gained some vertical mobility. They have sacrificed, though, their lateral mobilities (front-to-back and side-to-side). Watching then, one sees that they can only cling to their position, hoping not to fall. While they attempt to achieve height, they have neither the street level ability to jockey for position, nor the above's ability to move as hypertext, nor the camera's ability to zoom and focus. 
they provide a frame for and backdrop to the viewing experience. This mise-en-scene emphasizes the reading of the parade's development from below, even as the perspective prevents the viewer from reading the narrative of the parade as a whole. It also indicates more than the Tuanian experiential understanding of what is immediately in front of one person's eyes. Although it is still incomplete, the televisual perspective of the "Canyon of Heroes" occurring in the (inter)mediated view provided in NBC's coverage is not as incomplete as the operation of either the view from above or below on its own.

In both views, we are separated from the structures of power and the fleeting nature of popular authority. From above, we can see that we are separate from and limited by the structures of government and capitalism. From below, we see that these powers are too large to be fought against, given our small size and worth, and we are excluded from being the celebrated by barriers that force us to remain within the ranks of the celebrants. While this view of the both/and also is partial, it allows awareness of both views - from above and below. Although the viewer from above and below can see the structures of power from either view, by placing both together in the mediated context a fuller understanding of the structures of power in the "Canyon of Heroes" can be developed.

Even as the view from above serves to emphasize the celebratory nature of the spectacle that is unfolding in the streets, the view from below shows the viewer that there are mechanisms reinforcing the capitalist order of interaction. In a display of branding, both in the sense of merchandizing and cattle herding, a survey of those who are displayed most prominently as the ideal New Yorker reveals a person who is fully engaged in promoting consumerist capitalism. Those who wear Yankees hats, jerseys, or jackets are far more likely to be displayed in celebration than those who are not. Further, those who adopt the corporate image, by wearing pinstripes and painting team members' numbers on their faces, are even allowed to say, "I love Derek Jeter", to the folks sitting at home. For those standing on the sidewalk who are ill-prepared to participate as walking billboards, the camera shows us a vendor selling memorabilia, particularly T-shirts emblazoned with, "New York Yankees - 1998 World Champions". Indeed, the commentators make a special effort to find New York Mets fans converted to the Yankees and who sport new clothing to better advertise this fact. By incorporating the lived body into the space used by the parade, a cohesive 
whole is created wherein the two elements form a place out of the interaction of audience and scene. Although it is certainly permissible to wear one's Yankee gear almost anywhere, the consubstantiality provided by the shared clothing, along with the shared space and time, is an attempt to deepen the experience of the spectacle for the individual viewer. As such, these communicative acts create a common point of identification through personal garments that replicate or celebrate those of the corporatized image parading before them; the only path by which a "true" New Yorker can retain his/her identity is through consumerism.

Simultaneously, the parade sets the Yankees apart from the fans. Mayor Giuliani clearly notes a status difference between the Yankees players and the crowds. Giuliani's statement that the Yankees are a metaphor for New York is hyperbole. Yet, it has greater weight if we consider the symbolicity of the Yankees, a symbolicity that sets them apart from the fans and from the rest of baseball as well. Chadwin (1999: 7) tells us that "no ballclub has been more loved or more hated than the New York Yankees". There are several reasons for this extremity of emotions. Although four active Major League Baseball clubs have emerged from New York City, only the Yankees have spurred such extreme views. The New York (now San Francisco) Giants and the Brooklyn (now Los Angeles) Dodgers fail to inspire the hatred or devotion that the Yankees have, possibly because they have cut their moorings to New York City. The Mets have long been New York's "other team", usually gaining support only when facing off against the Yankees in the World Series - and usually losing. Marshall (1981: 2-3) offers five reasons that the Yankees are set apart from the rest of baseball. The Yankees 1) "win too much", 2) "win by buying the best players", 3) "get more attention than they deserve" media-wise, 4) "are arrogant, egotistical, and loudmouthed", and 5) "have Reggie Jackson in right field". Although Jackson has since retired (after a stint with the Angels), the other reasons remain. The Yankees take advantage of three positions within the power hierarchy that elevate them symbolically. They have an extremely large payroll. They are a prime entertainer in the world's largest media market. They have the most successful tradition in baseball. Because the Yankees are an exemplar of establishment power, both in baseball and in the corporate world, Sullivan and Powers (1997: 1) argue "the Yankees have performed with the success of a blue chip corporation. Rooting for New York... was like rooting for US Steel the players even wore pinstripes. The Yankees were crisp, dignified, 
and dispassionate". Their businesslike demeanor allows them to be a consistent producer of a rarefied product - World Championships and to manufacture it in monopolistic fashion. As players and people, the Yankees are made the elite of the elite. In all these ways, the Yankees are set apart symbolically.

The second way of setting the Yankees apart uses space to literalize the symbolic content of the Yankees as a special class. Physical barriers are placed between the crowd and the parade to reinscribe the "proper" place of both fan and player. The roadblocks are also staffed by police officers to ensure that fans will not cross this border. The Yankees are given floats that display them to the crowds. The crowds are limited to the sidewalks. As the crowds press inwards to get a better look at the players, the amount of space that a viewer on the street has to maneuver becomes even more limited. It seems that as the Yankees move by any point on the parade route, those who watch are imprisoned in the front by police barricades and in the back by people pushing to get closer to the border. The creation of spatial (em)placements of the crowd and the team, as well as dividing the groups through the use of the camera focus, creates the spatial circulation that limits the proper expression of "New Yorkness" and the relationship of team members within the space provided by the parade grounds. In another context, de Certeau comments on the relationship between space, ownership, and participation, when he notes,

Some common points must foster this circulation (of possibles) and mark off its paths. Thus a network of authorities is organized that are at once produced and received. They assure communication. But in that very way, they designate what no one can be identified with, nor subtracted from, without rejecting the necessary link between the relation with a truth and the relation with others (de Certeau 1997a: 14).

Although the space incorporates the audience into the perimeter of the place occupied by the New York Yankees physically (they literally stand on the side) and mentally (through shared clothing), there is a clear bounding-out of the audience in both senses as well. The definition of a true New Yorker is epitomized in this way, both by the production of the space as separating fans from players and by allowing this separation to be received through constant merchandising that encourages the (im)possible identification of the two groups. 
The obvious explanation of the relationship of physical space to the parade is easily demystified when these strands of symbols are woven together into a fuller text. The emplacements of capital, entertainment, and politics are clearly displayed. Similarly, there is a display of consumerism on the streets of New York. By not allowing the advertising to be seen as separate from the parade, however, the similar emplacement that occurs in televisual space is not as clearly seen. Rather, the parade and the commercials are inseparable by the end of the parade coverage; one cannot see the one without the other. The broadcasters make this clear when they thank the "special sponsors" for making the parade coverage possible (NBC 1998). The celebration of heroism, as integrated into the commodification scheme of the parade, may be representative of Barthes' "symbiosis" in which "the common ideology was never questioned again" (1972: 141). Thus while Soja may claim that people need "to reclaim and remystify hyperreality in a determined continuation of progressive political projects", the forces of government and capitalism can tug on each of these spatially symbolic strands to effectively mask the continuation of political and economic exploitation (1996: 279).

\section{Implications}

The New York Yankees parade lasted physically for three hours, and the space in which the parade took place reverted to normal use within six. The fact that the parade was part of an ongoing tradition in the use of space in New York City, however, makes it likely that the parade is more than a simple release of collective energy and celebration. As the NBC coverage stated, "It's immeasurable what this kind of thing can do for the psyche of a city" (1998), thus arguing that parades have an enduring impact on the mentality of the people of New York. Although the effects of a parade and a winning sports team may be immeasurable, the effect of parades and other mass-celebratory events can be measured directionally, if not quantitatively. Such effects are becoming more important to studies of the city, even those that seem not to impinge on spatial discussions. Indeed, as Soja argues, "A new field of critical urban studies is taking shape around the trialectical nexus of space, knowledge, and power and the interpretation of urban sites and spaces as simultaneously perceived, conceived, and lived" (1996: 236). While there has been an increased discussion of the importance 
of space generally, the conversation has been unbalanced when the implications of the use of space become apparent.

Many spatial analysts argue that theories, practices, and rhetorics based on the creative use of space allow for alternative strategizing on the part of displaced and marginal groups (see Casey 1993; Deutsche 1996; De Landa 1997; Soja 1996 for example). There seems to be a consensus on the part of spatial theorists that, because time and capital are controlled by forces of system(at)ic domination, spaces afford resistive ground. As indicated by Sennett's discussion of the New York City grid, the creative use of space "brings together people who are different, it intensifies the complexity of social life... All these aspects of urban experience - difference, complexity, strangeness - afford resistance to domination" (1994: 25-6). Space is, as these authors correctly note, often used in environmental and economic discussions that relate activities to the importance of a place (such as a forest or a factory) to a specific space (the region or the city). Moreover, in the cases that are favored by most spatial theorists, these spaces are used to resist the forces of political hegemony and economic imperialism to preserve the "identity" of an area. When the resistant movements are successful, it is because resistance based on the "sacred" nature of a space prevents its destruction. When the resistant movements fail, it is because the ability to relate to a space is destroyed by the hegemons and imperialists.

To end the spatial discussion there would ignore the use of space by forces that seek to disempower resistant movements. Spaces are used not only to resist domination but to enhance it. The New York Yankees parade illustrates this conservative corollary. Both (inter)mediation of the view from above and below and the (de)mystification that occurs in the parade lead to similar conclusions: parades and similar uses of public space can be used by conservative forces to reinforce structural economic and political orders. As Murdock might argue, "the most pervasive and central conditions of contemporary cultural practice stem from the dynamics of capitalism as they operate within the sphere of cultural production to organize the making of public meaning" (1995: 92). By combining governmental dynamics with Murdock's dynamics of capitalism, the conservative forces at play in the New York Yankees victory parade become clear. (Inter)mediation allows the viewer of the parade to see economic and political forces at play from above while simultaneously separating her/him from the ability to take action in a 
way other than that desired by the system. The parade viewer is given a narrative that ties success into paying homage to political and economic forces, decreasing the perception that resistance is a legitimate option. Although the political and economic powers seem frozen in the face of mass celebration, this is not the case. The practice of consumerist capitalism enacted during the spectacle and the police's provision of order show that the usual economic and political orders are still in place. Indeed, they are reinforced. Finally, when television is seen as a space, the (em)placement of the images of the parade and products create a remystification of the economic order, even as the parade's use of space seems to demystify that very order.

Not all uses of space are conservative, of course. Cox's (1969) arguments about the ludic festival and Bakhtine's (1988) discussion of the carnivalesque show that crowds can generate subversive or counterhegemonic power, even when dominant orders seek to suppress them. The chaotic and, occasionally, violent behavior during the Quebec Winter Carnival or the anti-WTO protests in Seattle show that space can be used in ways subversive to the establishment. The efforts at recolonization of military bases by musical groups like the Grateful Dead and Phish during concerts show that even the most powerful institutions in the United States are occasionally displaced for counterhegemonic performances. Even television has been a space that subversive individuals have tried to reclaim, as Michael Moore's TV Nation evidences. As great a challenge to dominant orders as these events may present, they need to be balanced against other uses of space that support the dominant system.

In short, while a riot or protest may show the use of space as resistant ground, events like the New York Yankees parade show that conservative forces also use space. Although most of the theorists of space see it as primarily resistant, de Certeau argues against such a utopian perspective. He writes that such symbolic weapons "would function less well in a more pragmatic organization, of an American type, for example" (1997b: 7). De Certeau is halfway correct. It is not simply that spaces do not function as well in an American system; it is that the effects of using space do not seem to agree with what spatial theorists want to see from the use of space as grounds for advocacy. Although resistant ground is provided for by spatial theories, it is equally important to see space as a topos for conservative advocacy as well. 


\section{References}

Achter, Paul and Jessica Brow. 2000. Rethinking the ethical and aesthetic qualities of rhetoric. Paper presented at the $86^{\text {th }}$ Annual Meeting of the National Communication Association, Seattle, Washington.

Bakhtine, Mikhail Mikhailovich. 1988. Rabelais and his World. Bloomington: Indiana UP.

Barthes, Roland. 1972. Mythologies. London: Jonathan Cape.

Baudelaire, Charles. 1997. The Parisian Prowler: Le spleen de Paris: Petits poèmes en prose. Tr. Edward K. Kaplan. Athens: University of Georgia Press.

Benjamin, Walter. 1986. Moscow Diary. Gary Smith ed. Cambridge: Harvard UP.

Blair, Carole, Julie R. Brown and Leslie A. Baxter. 1994. Disciplining the Feminine. Quarterly Journal of Speech, 84: 383-409.

Bourdieu, Pierre. 1999. Practical Reason. Stanford: Stanford UP.

Casey, Edward S. 1993. Getting Back into Place: Toward a Renewed Understanding of the Place-World. Bloomington: Indiana UP.

Certeau, Michel de. 1984. The Practice of Everyday Life. Berkeley: University of California Press.

—. 1986. Heterologies: Discourse on the Other. Minneapolis: University of Minnesota Press.

_. 1997a. Culture in the Plural. Minneapolis: University of Minnesota Press.

-1997b. The Capture of Speech and Other Political Writings. Minneapolis: University of Minnesota Press.

Chadwin, Dean. 1999. Those Damn Yankees: The Secret Life of America's Greatest Franchise. New York: Verso.

Cox, Harvey. 1969. The Feast of Fools: A Theological Essay on Festivity and Fantasy. Cambridge: Harvard UP.

Davis, Susan G. 1997. Spectacular Nature: Corporate Culture and the Sea World Experience. Berkeley: University of California Press.

Deutsche, Rosalyn. 1996. Eviction: Art and Spatial Politics. Cambridge: MIT Press.

Farrell, Thomas B. 1989. Media Rhetoric as Social Drama: The Winter Olympics of 1989. Critical Studies in Mass Communication, 6: 158182.

Fischer, Marilyn and Michael K. Ozanian. 1999. Cowboy Capitalism. Forbes, 164: 170-177.

Foucault, Michel. 1999. Religion and Culture. New York: Routledge. 
Giuliani, Rudolph. 1996, Nov. 3. WINS address (Mayoral address). http//: www.nyc.ny.us.

Goldberg, David Theo. 1998. Call and Response. Journal of Sport and Social Issues, 22: 212-223.

Harvey, David. 1989. The Urban Experience. Baltimore: Johns Hopkins UP.

Higgins, John M. 1999. The Art of the Media Deal. Broadcasting $\mathcal{B}$ Cable, 129: 70-7.

Katz, Elihu and Daniel Dayan. 1985. Media Events: On the Experience of Not Being There. Religion, 15: 305-314.

Kunstler, James Howard. 1993. The Geography of Nowhere: The Rise and Fall of America's Man-made Landscape. New York: Simon \& Schuster.

Landa, Manuel de. 1997. A Thousand Years of Nonlinear History. New York: Zone.

Marshall, Bob. 1981. Diary of a Yankee-hater. New York: F. Watts.

Mitrano, John R. 1999. The "Sudden death" of Hockey in Hartford: Sports Fans and Franchise Relocation. Sociology of Sport Journal, 16: $134-154$.

Murdock, Graham. 1995. Across the Great Divide: Cultural Analysis and the Condition of Democracy. Critical Studies in Mass Communication, 12: 89-95.

NBC. 1998. A Celebration for the Yankees. New York: NBC, Channel 4. Riggs, Karen E., Susan Tyler Eastman and Timothy S. Golobic. 1993. Manufactured Consent in the 1992 Olympics: The Discourse of Television and Politics. Critical Studies in Mass Communication, 10: 253-272.

Roche, Colleen and Jack Deacy. 1998. Mayor Giuliani announces that New York City will honor John Glenn and the crew of Discovery with ticker tape parade up the Canyon of Heroes on Monday, November $16^{\text {th }}$ (Press Release). http//: www.ci.nyc.ny.us.

Rothenbuhler, Eric W. 1989. Values and Symbols in Orientations to the Olympics. Critical Studies in Mass Communication, 6: 138-157.

Russell, Robert A. 1994. Devising a Cost-effective Schedule for a Baseball League. Operations Research, 42: 614-625.

Sennett, Richard. 1994. Flesh and Stone: The Body and the City in Western Civilization. New York: W.W. Norton.

Soja, Edward W. 1996. Thirdspace: Journeys to Los Angeles and Other Real-and-imagined Places. Oxford: Blackwell. 
Sullivan, George and John Powers. 1997. The Yankees: An Illustrated History. Philadelphia: Temple UP.

Trow, George W.S. 1997. Within the Context of No Context. New York: Atlantic Monthly Press.

Tuan, Yi-Fu. 1977. Space and Place: The Perspective of Experience. Minneapolis: University of Minneapolis Press.

Van Weert, Arjen and Jan A. M. Schreuder. 1998. Construction of Basic Match Schedules for Sports Competitions by Using Graph Theory. Lecture Notes In Computer Science, 1408: 201-210.

Yoder, Don G. 1997. A Model for Commodity Intensive Serious Leisure. Journal of Leisure Research, 29: 407-429. 